\title{
Does Night Care Affect Development? A Five-year Follow-up
}

\author{
Tokie Anme ${ }^{1, *}$, Emiko Tanaka ${ }^{1}$, Ryoji Shinohara ${ }^{1}$, Yuka Sugisawa ${ }^{1}$, Tako Watanabe ${ }^{1}$, Etsuko Tomisaki ${ }^{1}$, \\ Uma A. Segal ${ }^{2}$ \\ ${ }^{1}$ Graduate School of Comprehensive Human Sciences, University of Tsukuba, Tsukuba, 305-8575, Japan \\ ${ }^{2}$ School of Social Work, University of Missouri, St. Louis, 63121-4400, USA
}

\begin{abstract}
Japanese regulations have aimed to monitor night care for children since 1981, when a tragic accident took the life of a child in an unauthorized child care center. Nevertheless, concerns persist about the efficacy of the care of children outside the home during the nighttime hours. This longitudinal project assessed the development and adaptation of children who had been in night care for a period of five years. Parents and child care professionals completed surveys: The former about the home environment and their own perceptions of their experience of childrearing, and the latter about the children's development. The results suggest that factors in the home environment, rather than center-based care, explain developmental risks.
\end{abstract}

Keywords Night Child Care, Child Development, Child Rearing Environment, Self-Efficacy

\section{Introduction}

Discussions about the implications of child care, its quality and its quantity, on children in middle childhood and adolescence abound, and in recent years several have explored the implications with mixed findings[1][2]. Japan is particularly unique in that it has been responsive to the growing needs of working mothers for quality child care during evening and night time hours. High-quality center-based night care is essential when parents are employed for long hours that also include evening and night hours. Since 1981, Japan has authorized seventy authorized night care facilities; these centers are licensed by the national government and are recognized as meeting quality care standards which has been particularly important after highly publicized reports of several involuntary homicides (child deaths resulting from neglect) in low-quality "Baby Hotels"[3]. The "Baby Hotels" are child care facilities that provide round-the-clock care for children from birth to age seven years. Despite the move to authorize care, there continues to be shortages, and over 120,000 children still use non-authorized, sub-standard Baby Hotels[4]. Although the study of these facilities can be particularly en lightening, research access is limited the impact on children's development is outside the scope of this study.

* Corresponding author:

anmet@md.tsukuba.ac.jp (Tokie Anme)

Published online at http://journal.sapub.org/edu

Copyright (C) 2012 Scientific \& Academic Publishing. All Rights Reserved
Hence, this study focuses on the implications of extended nighttime hours in authorized licensed child care facilities for the social and behavioral develop ment of children.

Quality of care must be considered if the effects of early childcare on future development are to be understood[2]. Findings from studies of quality care itself appear to be mixed, particularly in the long term. Some indications are that children may be less anxious and have less problematic transitions to school if they have been participants in better quality centers, and children placed in nonmaternal care in the first three years of their lives have been found to evidence higher achievement and lower behavioral problems in adolescence[1]. However, an earlier longitudinal study, suggests that the positive effects of high quality center care facilities may not differentiate children as they grow older. Andersson[5] found that by age 13 years, there were no discernible differences between children who had experienced high quality childcare and those who had not.

While studies of nonmaternal care are prevalent, there is less empirical information regarding the effects of placing children in such care for extended periods of time (11+ hours). Since the formalization of center-based night care is rare in nations outside Japan, extended care facilities may not be the subject of research focus. Even in Japan, there continues to be a paucity of literature in this area, and few studies have assessed the influence of center-based night care on child development[4]. While Jafee and colleagues[1] report no correlation between age of entry into nonmaternal care and intellectual and behavioral development, their meta-analysis fails to address the experience of children in night care facilities. Night care facilities are those that 
provide childcare well after 10:00 pm, and children may stay there as late as 2:00 am.

This study sought to determine if, after five years, there is a correlation between (1) the type of center-based care (day vs. night) and young children's social competence and vocabulary/motor/intelligence development, and (2) the childrearing environment provided by parents and children's development.

\section{Methods}

\subsection{Setting and Sample}

All govern mentally authorized child-day-care and child-n ight-care centers across Japan participated in the study. Centers unauthorized by the government were excluded because the quality of care they provide is variable and also because they rarely cooperate with external investigators. All parents of children at the authorized facilities and all the service providers participated in the study. Parents with a child who was a year old were surveyed regarding their ho me environments, and service providers evaluated the development of each child in the facility. The valid response rate was $71.5 \%(1,242)$ for parents as well as for service providers. Children with diagnosed disabilities and health problems were excluded from the study as these characteristics were expected to confound results. Of the 1,242 children sampled at age one, $888(71.5 \%)$ were sampled again at age five years, with both parents and service-providers evaluating the children. Table 1 provides the gender and age composition of the child population that was evaluated and the family structure, siblings, economic status, type of child care, and occupations of the parents. The distribution of boys, 449 (50.6\%), and girls, 439 (49.4\%), was fairly even.

The ethics committee of the University of Tsukuba approved this research.

\subsection{Overview of Measures}

Indicators of child-care quantity, quality, stability, and type of professional childcare (day or night care) along with measures of family backg round, parenting capabilities, child characteristics and child adaptation to center-based care were obtained from two questionnaires. These questionnaires were completed by parents responsible for the children in the first sixyears of their lives and were (1) a Japanese version of a questionnaire on the child-rearing environment[6] and (2) a questionnaire seeking respondents' perceptions of their self-efficacy and support for childcare[7][8].

Childcare professionals evaluated children's social comp etence, communication, and development in vocabulary acquisition, motor development, and intelligence capabilities (vocabulary/motor/intelligence) for each child, using developmental scales that have been standardized in Japan[9]. All childcare professionals, already qualified in child development, were provided with a minimum of eight hours of training to translate children's development into the measures indicated on the child development scale. These variables, selected to be consistent with earlier studies by the NICHD[10], were then used to explore the relationship between type of care and child development.

The two categories of childcare were identified by the time at which children generally left the center-based care: "day care" (leaving facility by 7:00pm), and "night care" (leaving facility after 10:00pm). Of the subjects, 824 (92.8\%) were enrolled in "day care" and 64 (7.2\%) in "night care".

Family and child variables included the child's gender and age, child develop ment, parent behavior, parent efficacy for care, and the existence of childcare support. Professional caregivers measured child development along six variables (gross and fine motor skills, social competence, communica tion, vocabulary, and intelligence development) that were categorized into 2-point items (normal, delayed) (See Table 2). These service providers in the center-based childcare facilities also evaluated the health and disabilities of the children.

Parent behavior was assessed based on dichotomous responses (yes/no) to thirteen activities in the home environment. For analysis, the 25th percentile point was used as a cut-off for non-nominal items. Parents' self-reports on the five-po int scale, (where $1=$ always, $2=$ often, $3=$ somet ime s, 4=rarely, 5=never) of parental efficacy for care reflected the parent's affective state. Emotions evaluated were depression, anxiety, instability, stress, and exhaustion.

\section{Results}

The items of child development, positive qualities of parents' behavior, parent efficacy for care, and existence of support for care at time one (T1) were assessed for their correlations with the type of center-based care (day care or night care) in which the child was enrolled. The Statistical Analysis System (SAS) statistical package was used for analysis. Multiple regression analyses were used to predict child develop ment (delayed or normal) and child adaptation to center-based care (adapted or not) after five years[time two (T2)]. Identified independent variables for these analyses were type of care ("night care" or else), positive qualities in parental behavior (13 items), parent efficacy for care, and the existence of support for care[as reported when the child was a year old (T1)]. An odds ratio was calculated to clarify the magnitude of effects, and using multiple logistic analysis, estimated the strength of relations. All results were assessed significant at the $\mathrm{p}<.01$ level or the $\mathrm{p}<.05$ level, however, the variable "type of care" was not a relevant variable in all analyses.

Table 2 reports that a small nu mber of children evidenced delays in development and specifies the areas of risk related to the child's development. The overwhelming majority of children appear to have no developmental delays in the areas assessed. Percentages of developmental risks are low, 
ranging from $1.4 \%$ to $2.7 \%$.

Data analyses found no significant correlations between type of care (day care or night care) or any variab les used to assess the development of the child at age six years. However, significant correlations were found between some variables measured at time one[T1 (when the child was a year old)] and the child's development at time two[T2 (when the child was six years of age)].

As is indicated in Table 3, a chi-square test was applied to the data to assess the development of the children at age six years (T2). Baseline fine motor skills, social competence and communication development, as measured at time one (T1) was significantly related to intelligence development five years later (T2). Support from spouse (T1) was significantly related to vocabulary and intelligence development five years later (T2); appropriate parental response to children's mistakes (T1) was related to vocabulary development (T2), perceived support for child care (T1) was correlated with intelligence development (T2), and communication with parents (T1) was associated with fine motor development (T2). Other correlations were found to be insignificant.

Table 4 indicates the results of the multiple regression analysis. Support from spouse (T1) was significantly related to vocabulary development five years later[T2 (odds ratio 4.07)], appropriate response to mistakes (T1) was related to vocabulary development[T2 (odds ratio 4.35)], and going to the park (T1) was related to fine motor development[T2 (odds ratio 2.86)]. Thus, findings suggest that when the spouse was engaged in the child rearing, vocabulary development was enhanced. There was also a positive correlation between the development of vocabulary and appropriate parental responses to the child's mistakes. Interestingly, fine motor development was positively associated with increased visits to the park.

\section{Discussion}

Center-based care night, in which child ren stay past 10:00 $\mathrm{pm}$, is unique in Japan, and few studies have focused on this important, but rarely found, opportunity for child care services. In addition to exploring the differences in the effects of night care and day care on child development, this study assessed the correlations between variables in the child's ho me environment when the child was a year old with the child's development at age six years. All night care centers in this study had passed governmental standards and attempted to ensure that the natural circadian rhythms for children, such as sleep, eat, and play, were well maintained. The day care centers that were involved in this study had also passed governmental standards and were comparable in quality to the night care centers. Results of this study indicate that it is neither the type of care nor the length of time that children are in center-based care that is correlated with development, rather it is salient factors in the home environment that are correlated with development and developmental delays.

As the first nation-wide cohort study of center-based care that assesses child develop ment and adaptation based on the complex relations among factors, including the quality of parent behavior, this study provides unique insight into our understanding of the correlation between child care options, the home environment, early development, and further development in subsequent years. Outside Japan, several large-scale, center-based childcare studies have been conducted and have documented relations between early and/or extensive childcare experience, noncompliance, and problem-behavior, even after controlling for selection effects[11]-[16]. Since professionally delivered nighttime child care is relatively rare outside Japan, there is a paucity of research on the implications of this form of care. Nevertheless, the current investigation provided results that contradicted some earlier studies, finding little evidence that the time children spent in non-parental care, whether in the day or the night, in the first years of life is, in and of itself, systematically related to children's self-control, compliance, or problem behavior by age six years.

The general absence of strong or consistent effects of the variable "type of care," in prior studies may not be surprising. Despite continued concerns about the length of time children are in non-parental childcare, contemporary theory about the complex ecology of child development suggests that many additional factors may be more influential in affecting a child's progress. The compensatory-process and lost-resour ce perspectives[2] suggest that the effects of parental characteristics, including poor mental health and lower socioeconomic status, may be compensated for by quality nonmaternal care. Thus, if the home environ ment is lacking, high quality professional child care can help mitigate difficulties in the former. This led to the expectation that the interaction between quality and quantity of child care and child development may be more significant than would the main effects of the type of care. The type of professional child care (day or night), in this study, was not related to the child's development as measured at age six; quality of the home environment and developmental abilities in the early years, as measured at baseline (T1) through the reports of parents and child care professionals, were the most consistent predictors of child development at $\mathrm{T} 2$.

While quality of care may have been a reflection of the maternal and family characteristics that distinguished between families that participated in this study, and those who did not, it is proposed that the high response rate and the highly homogeneous nature of Japanese society may mitigate these effects. That parental behavior was more strongly related to child development and adaptation than was whether children were in "day" or "night" child-care is consistent with results of prior examinations of the effects of childcare on infant-mother attachment[17]. It may, further, be self-explanatory that baseline development is correlated with development as the child grows older, however, this study does suggest that the quality of the ho me environ ment may influence this development. Thus, the principal implication of this large-scale, multisite research project is that parent behavior may be more important in explaining 
children's early social, vocational, motor and intelligence development and adaptation than the type of professional child care services the parents utilize.

Literature does suggest, however, that center-based care exerts some influence upon children. Studies report that the quality of care is the most consistent child-care predictor, with higher quality of care relating to greater social competence and cooperation and less problem behavior at both two and three years of age[18]. On the other hand, there is some indication that length of time in nonmaternal care may be correlated with higher academic achievement but more risk-taking and impulsive behavior in adolescence[2]. More time in care and more variable care arrangements (i.e., less stable care) are predictors of negative outcomes for children at 2 years of age[19].

\section{Conclusions}

The series of studies on night care conducted by Anme and her colleagues continue to result in findings that suggest that while there is some minor difference in the effect of "night", rather than "normal," care on the development of children, major factors that seem to affect child development and adaptation are early development and parental characteristics. These findings do have particular significance for educators and service providers working with families of young children. Home life and the psycho-social health of the parental caregiver, including his/her self-confidence and the availability of childcare assistance appear to be essential ingredients in the development of a child; these evidenced themselves at both $T_{1}$ and $T_{2}$ of this longitudinal study. In home assessments by public health nurses, educators, and other professionals with in-home access, should be followed-up, as necessary, by parenting classes and support services. The consistency of these findings over two time periods suggest that targeting young parents for preventative services can enhance both the development of children as well as increase parental sense of competence and ability to cope with the responsibility of raising children. Replication studies may seek to assess additional reliability of these data, Additional longitudinal research by Anme and her colleagues, will continue to follow the current sample to assess development and evaluate effects of child-care that may emerge later in development.

\section{ACKNOWLEDGEMENTS}

We express our deepest gratitude to Japan Night Child Care Alliance, President Amahisa, Vice-President Edamoto, all the participants and staffs.

This research was supported by the Grants-in-Aid for Scientific Research (23330174) and Research Institute of Science and Technology for Society.

\section{REFERENCES}

[1] Jaffee SR., Hulle CV., Rodgers JL. Effects of Nonmaternal Care in the First 3 Years on Children's Academic Skills and Behavioral Functioning in Childhood and Early Adolescence: A Sibling Comparison Study, Child Development, 82, 1076-1091, 2011.

[2] Vandell DL., Belsky J., Burchinal M. Do Effects of Early Child Care Extend to Age 15 Years? Results From the NICHD Study of Early Child Care and Youth Development, Child Development, 81, 737-756, 2010.

[3] Oishi AS. Child care in a low birth society. In Coulmas, F., Conrad, H., Schad-Seifert, A. \& Vogt, G. (eds). The demographic challenge: A handbook about Japan, Leiden, The Netherlands: Brill, 277 - 272, 2008.

[4] Anme T., Segal UA. Effectiveness of Japan's extended/night child care: A five-year follow up, Procedia Social and Behavioural Sciences, 2, 5573-5580, 2010

[5] Andersson B. Effects of day care on cognitive and socio-emotional competence of thirteen-year -old Swedish schoolchildren, Child Development, 63, 20-36, 1992.

[6] Caldwell BM. \& Bradley RH. Home observation for measurement of the environment. Little Rock, Arkansas: University of Arkansas at Little Rock, 1984.

[7] Anme T. Risk assessment using evaluation of environmental stimulation in Japan, National Roundtable on Child Protective Services Risk Assessment,9, 37-47, 1995.

[8] Anme T. \& Takayama T. Evaluation of home stimulation for normal and handicapped children in Japan. In Takayama, T. (ed). Early Childhood Toward the 21st Century, (pp. 427-430). Hong Kong: Yew Chung Education Publishing Company, 1990.

[9] Anme T, Child development and childcare in Japan, Journal of Early Childhood Research, 8(2), 193-210, 2010

[10] NICHD Early Child Care Research Network. Child outcomes when child care center classes meet recommended standards for quality, American Journal of Public Health. 89, 1072-1077, 1999.

[11] Bates J., Marvinney D., Kelly T., Dodge K., Bennett T., Pettit G. Child-care history and kindergarten adjustment. Developmental Psychology, 30(5), 690-700, 1994.

[12] Baydar N., Brooks-Gunn N. Effects of maternal employment and child care arrangements on preschoolers' cognitive and behavioral outcomes: Evidence from the children of the National Longitudinal Survey of Youth. Developmental Psychology, 27, 932-945, 1991.

[13] Belsky J., Eggebeen, D. Early and extensive maternal employment and young children's socioemotional development: Children of the National Longitudinal Survey of Youth. Journal of Marriage and Family, 53, 1083-1110, 1991.

[14] Borge A., Melhuish E. A longitudinal study of childhood behavior problems, maternal employment, and day care in rural Norwegian community. International Journal of Behavioral Development, 18, 23-42, 1995.

[15] Park K., Honig A. Infant child care patterns and later teacher ratings of preschool behaviors. Early Child Development and 
Care, 68, 89-96, 1991.

[16] Vandell DL., Corasaniti MA. Child care and the family: Complex contributors to child development. New directions for child development, 49, 23-37,1990.

[17] NICHD Early Child Care Research Network. Relations between family predictors and child outcomes: Are they weaker for children in child care? Developmental Psychology,
34(5), 1119-1128, 1998.

[18] NICHD Early Child Care Research Network. The NICHD Study of early child care. Psychiatric Times, 15(3), 71-72, 1998.

[19] NICHD Early Child Care Research Network. Child care and mother-child interaction in the first three years of life. Developmental Psychology, 35(6), 1399-1413, 1999. 